\title{
Single nucleotide polymorphisms of protein tyrosine phosphatase 1B gene are associated with obesity in morbidly obese French subjects
}

\author{
S. Kipfer-Coudreau ${ }^{1}$ D. Eberlé1, 2 - M. Sahbatou ${ }^{3}$ A. Bonhomme B B. Guy-Grand $^{1} \cdot$ P. Froguel F P. Galan $^{6}$ • \\ A. Basdevant ${ }^{1} \cdot$ K. Clément ${ }^{1,5}$ \\ ${ }^{1}$ INSERM Avenir and EA 3502, Nutrition Department, Paris VI University, Paris, France \\ 2 INSERM U465, Paris VI University, Paris, France \\ ${ }^{3}$ Centre d'Etude du Polymorphisme Humain, Paris, France \\ ${ }^{4}$ CNRS UPRESA 80-90, Lille Institute of Biology, Pasteur Institute, Lille and Hammersmith Genome Centre, Imperial College, \\ London, UK \\ ${ }^{5}$ Hôtel-Dieu Service de Nutrition, Paris Cedex, France \\ ${ }^{6}$ INSERM/INRA/CNAM, Institut Scientifique et Technique de la Nutrition et de l'Alimentation, ISTNA/CNAM, Paris, France
}

\section{Abstract}

Aims/hypothesis. The development of insulin resistance may contribute to the occurrence and progression of the metabolic syndrome associated with obesity. Components contributing to the insulin pathway and its regulation are good candidates for the molecular study of metabolic syndrome pathogenesis. Protein tyrosine phosphatase 1B (PTP 1B) is an important negative regulator of insulin. We investigated whether PTP $1 B$ SNPs are associated with obesity and obesityrelated traits as well as global metabolic syndrome in morbidly obese subjects.

Methods. Untranslated and coding regions of the PTP $1 B$ gene were screened in groups of non-diabetic and diabetic obese subjects and in non-obese subjects. Unrelated morbidly obese $(n=711)$ and non-obese $(n=427)$ French Caucasian subjects were genotyped for a case-control study.

Results. Six SNPs were identified: two rare variants were located in $5^{\prime} \mathrm{UTR}(-109 \mathrm{C}>\mathrm{T}$ and $-69 \mathrm{C}>\mathrm{T})$, two in the intronic regions (IVS3+38 G>T and IVS5+ 3666delT) and two have been described previously (P303P in exon 8 and P387L in exon 9). A case-control study showed an association between the frequent IVS5+3666delT SNP and obesity $(p=0.02)$. In the obese group, associations between PTP $1 B$ SNPs and features of dyslipidaemia were found. P303P was associated with lower apolipoprotein A1 levels $(p=0.05)$ whereas $\mathrm{P} 387 \mathrm{~L}$ was associated with higher triglyceride $(p=0.0003)$, apolipoprotein $\mathrm{B}(p=0.09)$ and lipoprotein a concentrations $(p=0.006)$.

Conclusions/interpretation. Our results support the hypothesis that the PTP $1 B$ gene contributes to the polygenic basis of obesity. PTP $1 B$ SNPs may interact with environmental factors to induce more severe phenotypes, e.g. atherogenic dyslipidaemia, in morbidly obese subjects.

Keywords Association study - Insulin · Metabolic syndrome $\cdot$ Obesity $\cdot$ PTP 1B $\cdot$ Single nucleotide polymorphisms
Received: 13 January 2004 / Accepted: 14 May 2004

Published online: 3 July 2004

C Springer-Verlag 2004

K. Clément (®)

Hôtel-Dieu Service de Nutrition,

1 place du parvis Nôtre-Dame, 75181 Paris Cedex 04, France

E-mail: karine.clement@htd.ap-hop-paris.fr

Tel.: +33-1-42348670, Fax: +33-1-40510057

Abbreviations: LD, linkage disequilibrium - PTP 1B, protein tyrosine phosphatase $1 \mathrm{~B} \cdot \mathrm{SNP}$, single nucleotide

polymorphism - SREBP-1, sterol regulatory element binding protein 1 . UTR, untranslated region

\section{Introduction}

A clustering of several cardiovascular risk factors, comprising, in particular, obesity, as well as Type 2 diabetes, hypertension and dyslipidaemia, is described as metabolic syndrome. The presence of these metabolic diseases is highly associated with increased cardiovascular mortality in large human populations [1]. Many studies suggest that the development of obesityassociated insulin resistance may contribute to the occurrence and progression of metabolic syndrome $[2,3$, $4,5]$. Components contributing to the insulin pathway 
and its regulation are good candidates for the molecular study of the pathogenesis of metabolic syndrome.

The binding of insulin to the insulin receptor involves its autophosphorylation on three critical tyrosine residues located in the $\beta$ subunit tyrosine kinase regulatory domain. Insulin receptor activation triggers phosphorylation cascades of various substrates. IRS-1 is one of the main substrates targeted by insulin receptor activation $[6,7]$. The reversible phosphorylation of tyrosyl residues is a key process that modulates intracellular insulin signalling.

As it catalyses insulin receptor and IRS-1 dephosphorylation, protein tyrosine phosphatase 1B (PTP 1B) is a negative regulator of insulin action $[8,9,10]$. Mice deficient in PTP 1B exhibit increased insulin receptor phosphorylation and higher insulin sensitivity in liver and skeletal muscle $[11,12]$ but not in white adipose tissue. These PTP $1 B$-invalidated mice are resistant to weight gain when fed a high-fat diet [11]. Decreased lipogenesis and adiposity were described in obese $o b / o b$ mice treated by PTP 1B antisense oligonucleotide [13]. Lower adiposity in these mice was associated with a down-regulation of sterol regulatory element binding protein 1 (SREBP-1), a transcription factor involved in glycolysis, lipogenesis and adipogenesis [14]. PTP 1B up-regulates SREBP-1 gene expression in hepatocytes via increased phosphatase $2 \mathrm{~A}$, thus mediating hepatic lipogenesis [15]. PTP 1B could thus be involved in the polygenic basis of obesity, metabolic syndrome and related disorders in humans via its role in the modulation of insulin sensitivity and energy metabolism.

In humans, the PTP $1 B$ gene is located on the 20q13.1-13.2 chromosomal region, a locus linked to obesity and Type 2 diabetes in French Canadians [16, 17]. Association studies showed that rare single nucleotide polymorphisms (SNP) in the PTP $1 B$ gene were associated with Type 2 diabetes in Danish [18] and Canadian [19] subjects and with features of insulin resistance in healthy, normal-weight Italians [20]. No study has analysed $P T B \quad 1 B$ gene SNPs in morbidly obese subjects that are characterised by a high occurrence of diseases associated with metabolic syndrome.

We hypothesised that polymorphisms in the $P T P 1 B$ gene could be associated with morbid obesity and/or obesity-related traits such as insulin resistance, Type 2 diabetes, hypertension and dyslipidaemia, as well as general metabolic syndrome. In this study, we present the genetic molecular screening of the PTP $1 B$ gene in diabetic and non-diabetic obese French patients as well as association studies of identified SNPs in morbidly obese Caucasian subjects.

\section{Subjects and methods}

Subjects involved in the primary screening. To maximise the detection of SNPs related to human metabolic diseases, $P T P 1 B$ gene screening was done first in three selected groups.
Table 1. Clinical and biological phenotypes of the obese and control groups studied

\begin{tabular}{lcc}
\hline & Obese group & Control group \\
\hline Number $(n)$ & 711 & 427 \\
Men/Women & $179 / 532$ & $217 / 210$ \\
Age (years) & $45.1 \pm 11.9$ & $53.3 \pm 6$ \\
BMI (kg/m ${ }^{2}$ ) & $47.3 \pm 7.4$ & $21.9 \pm 1.7$ \\
Type 2 diabetes & $33.2 \%$ & $0 \%$ \\
Hypertension & $43 \%$ & $0 \%$ \\
Metabolic syndrome prevalence & $72.9 \%$ & $\mathrm{Na}$ \\
Glucose (mmol/l) & $6.9 \pm 2.9$ & $5.5 \pm 0.6$ \\
Insulin (U/L) & $18.8 \pm 13.3$ & $\mathrm{Na}$ \\
HOMA index (\%) & $100 \pm 59$ & $\mathrm{Na}$ \\
Triglycerides (mmol/l) & $1.8 \pm 1$ & $1.0 \pm 0.7$ \\
Total cholesterol (mmol/l) & $5.3 \pm 1.1$ & $5.9 \pm 0.9$ \\
HDL cholesterol (mmol/l) & $1.1 \pm 0.32$ & $\mathrm{Na}$ \\
\hline
\end{tabular}

Results are given as means $\pm \mathrm{SD}$; na: data not available

The first group comprised 39 non-diabetic obese subjects (22 men/17 women) with a mean age of $51.0 \pm 0.8$ years, BMI of $42.0 \pm 1.2 \mathrm{~kg} / \mathrm{m}^{2}$ and fasting glycaemia rate of $5.3 \pm 0.06 \mathrm{mmol} / \mathrm{l}$. The second group comprised 29 Type 2 obese diabetic subjects ( 15 men/14 women) with a mean age of $51.3 \pm 0.6$ years, BMI of $48.4 \pm 1.3 \mathrm{~kg} / \mathrm{m}^{2}$ and fasting glycaemia rate of $9.7 \pm 0.7 \mathrm{mmol} / \mathrm{l}$. The third group comprised 33 non-obese, non-diabetic control subjects (13 men/20 women) with an average BMI of $19.1 \pm 0.1 \mathrm{~kg} / \mathrm{m}^{2}$ and fasting glycaemia rate of $5.3 \pm 0.06 \mathrm{mmol} / \mathrm{l}$.

Subjects involved in the genetic association study. A case-control study of obesity was carried out first on 711 severely obese, unrelated Caucasians and 427 non-obese, non-diabetic, unrelated subjects (Table 1). Within the obese group, an association study between the PTP $1 B$ SNPs and qualitative and quantitative traits was also done. Obese subjects were randomly chosen from a panel of 1000 obese French patients collected for the study of genetic determinants of obesity on the basis of a BMI above $40 \mathrm{~kg} / \mathrm{m}^{2}$. Obese Caucasian subjects were recruited firstly from the Nutrition Department of Hôtel-Dieu hospital (France) and secondly through a French media campaign via a toll-free number [21]. Our purpose was to eliminate possible selection bias introduced by hospital-based collection of obese patients, who are more likely to be seen in a hospital if they also have an associated co-morbidity. For all the subjects, the complete medical history of each patient was obtained by questionnaire. Diagnosis of Type 2 diabetes was based on 1997 American Diabetes Association (ADA) criteria. Diagnosis of hypertension and dyslipidaemia were based on hypotensive or hypolipidaemic treatments respectively and/or on WHO criteria [22]. WHO criteria were used to define metabolic syndrome as: insulin resistance or Type 2 diabetes and the presence of at least two of the following criteria: abdominal obesity (WHR $>0.9$ or $\mathrm{BMI} \geq 30 \mathrm{~kg} / \mathrm{m}^{2}$ ), dyslipidaemia (serum triglycerides $\geq 1.7 \mathrm{mmol} / \mathrm{l}$ or HDL-cholesterol $<0.9 \mathrm{mmol} / \mathrm{l}$ ), hypertension $(\geq 160 / 90 \mathrm{~mm} \mathrm{Hg}$ ), or microalbuminuria. Despite the different modes of recruitment, no difference was observed between obese patients recruited by the Nutrition department and those recruited by the media campaign.

Healthy control subjects were selected from French Caucasians participating in the prospective SU.VI.MAX study [23]. SU.VI.MAX (SUpplementation en VItamines et Minéraux AntioXidants) was a randomised, double-blind, placebo-controlled, primary-prevention trial designed to test the 
Table 2. Primer sequences used for PCR amplification of the PTP 1B segments, SSCP heteroduplex gel analysis and sequencing of variants

\begin{tabular}{|c|c|c|c|c|}
\hline $\begin{array}{l}\text { Fragments } \\
\text { amplified }\end{array}$ & Primers "forward" & Primers "reverse" & Size $(\mathrm{pb})$ & $\begin{array}{l}\text { Annealing } \\
\text { temperature }\left({ }^{\circ} \mathrm{C}\right)\end{array}$ \\
\hline 5'UTR/exon 1 & CAGGCGTGATGCGTAGTT & CTGGAGGTCTGAGGGGAT & 311 & 57 \\
\hline 3 & CTGAGTTCTGGTTTGTCT & CAGATTTTATTTGAGGTG & 206 & 50 \\
\hline 4 & AGCCTCAGCCACCACTCT & GATCACATACACAGCAAATG & 263 & 57 \\
\hline 5 & CATAGAAAAACTGCCATA & TGAAGTGCTGAAGTGTGTG & 221 & 52 \\
\hline 8 & TCGCCAAGCCGTCACCTCT & TCATTTCСССТСАСССCA & 357 & 62 \\
\hline 9 & САTCTCTGCCCTCTGATTCC & CGCGTCTGTCAGTGGAAACA & 243 & 54 \\
\hline 10/3'UTR & GTCATGCATGAGGCGACAGC & GGGTTTTAGTGCAGAACCAA & 243 & 56 \\
\hline
\end{tabular}

efficacy of daily supplementation with antioxidant vitamins and minerals at nutrition-level doses in reducing mortality and the incidence of cancers and ischaemic heart diseases in a French general adult population. Subjects enrolled in the study were followed for up to 8 years with yearly visits. In this population, the knowledge of the weight history of patients in the control group was obtained by questionnaire and regular weight measurements. Using the weight records, we were able to select people who had never been obese. This group was thus composed of thin and healthy subjects and may represent a supranormal control group. The appropriate ethics committee (CCPPRB Hôtel-Dieu and Cochin Hospital) approved the study protocol. Written informed consent was obtained from all subjects.

Laboratory tests. Biochemical variables were measured after an overnight fast. Glycaemia ( $\mathrm{mmol} / \mathrm{l})$, triglyceridaemia, total and HDL cholesterolaemia $(\mathrm{mmol} / \mathrm{l})$ and apolipoprotein $\mathrm{B}$ and A1 levels ( $\mathrm{g} / \mathrm{l})$ were measured enzymatically. Insulinaemia (mU/l) was measured immunologically (IRMA, Immunotech, BioRad-Pasteur IRMA, France). Insulin sensitivity was evaluated using the HOMA index [24].

SNP detection by PCR-SSCP and direct sequencing. DNA was extracted from EDTA whole-blood samples using the Puregene kit (Gentre, Minneapolis, Minn., USA). The ten coding exons of the PTP $1 B$ gene were amplified separately by selected primer pairs including intron-exon junctions (Table 2). All PCRs were carried out in a final reaction volume of $25 \mu \mathrm{l}$, containing $100 \mathrm{ng}$ of human genomic DNA, $2.5 \mu \mathrm{l} 10 \times$ amplification buffer, $200 \mu \mathrm{mol} / \mathrm{l}$ of dNTP, $12.5 \mathrm{pmol}$ of each primer and 0.5 units of Taq polymerase Gold (Applied Biosystems, Paris, France). PCR reactions were done according to the following protocol: denaturation for 12 minutes at $94{ }^{\circ} \mathrm{C}$, followed by 35 cycles of denaturation $\left(94{ }^{\circ} \mathrm{C}, 40 \mathrm{~s}\right)$, annealing (40-s sequences, annealing temperatures for each primer set given in Table 2), extension $\left(72{ }^{\circ} \mathrm{C}, 40 \mathrm{~s}\right)$ and a final 12 -min extension at $72{ }^{\circ} \mathrm{C}$. PCR samples were analysed by Single Strand Conformation Polymorphism (SSCP) [25]. Each exon presenting a "shift" after SSCP gel migration was directly sequenced in both directions using a LICOR 400 automated sequencer (LiCor Sciencetec, Courtaboeuf, France).

SNP genotyping by PCR-RFLP. Genotyping of obese and nonobese subjects was done using the PCR-RFLP method and repeated twice for each sample. PstI, HhaI, EarI, DdeI and BsII restriction enzymes (New England Biolabs, Mass., USA) were used to study $-109 \mathrm{C}>\mathrm{T},-69 \mathrm{C}>\mathrm{T}$, IVS5 +3666delT, P303P and P387L SNPs respectively.
Statistical analysis. Statistics were done with JMP software (SAS Institute, Cary, N.C., USA). Hardy-Weinberg's equilibrium was tested with the chi square test. Categorical variables were compared between groups using the chi square test. Continuous clinical and biological variables were analysed using either one-way analysis of variance or Wilcoxon and KruskalWallis tests depending on the shape of the distribution curves. For distribution that was positively skewed, a log power transformation was applied for the tests. Clinical and plasma biological data were adjusted for age, sex and BMI when necessary. In each test, a $p$ value of less than 0.05 was considered statistically significant. Haplotype reconstruction was done from population genotype data, using the PHASE program [26]. Then, linkage disequilibrium (LD) and the standardised LD coefficient between pairs of SNP (D') were calculated using ARLEQUIN software (http://anthro.unige.ch/arlequin). Statistical significance was assessed by $p$ values of the exact test of LD [27].

\section{Results}

Mutation analysis of the PTP $1 B$ gene. Exons of the $P T P I B$ gene were amplified and sequenced, including the $5^{\prime}$ untranslated region (UTR) from position -179 before the translation start site and the $3^{\prime}$ UTR to position +152 after the stop codon. Six variants were identified (Fig. 1). Four variants were new SNPs located either in $5^{\prime} \mathrm{UTR},-109 \mathrm{C}>\mathrm{T}$ and $-69 \mathrm{C}>\mathrm{T}$, or in intronic regions, IVS3+38T $>$ G and IVS5+3666delT. The two other variants were described previously as a silent $\mathrm{P} 303 \mathrm{P}(\mathrm{CCC} \rightarrow \mathrm{CCT}$ in exon 8$)$ and a missense P387L (CCA $\rightarrow$ CTA in exon 9) mutation.

Case-control study. Genotypes and allelic frequencies of five PTP $1 B$ SNPs are presented in Table 3. All

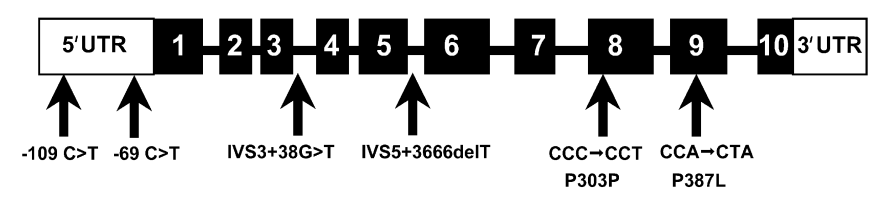

Fig. 1. Description of the PTP $1 B$ gene and of SNPs found. For each SNP, the most frequent allele is listed first, followed by less frequent identified alleles 
Table 3. Genotypes and allelic frequencies $(\%)$ for the genotyping variants of the PTP $1 B$ gene

\begin{tabular}{|c|c|c|c|c|c|c|c|c|c|c|c|}
\hline \multirow[t]{2}{*}{ SNPs } & \multicolumn{5}{|c|}{ Morbidly obese group } & \multicolumn{5}{|c|}{ Control group } & \multirow{2}{*}{$\begin{array}{l}p \text { value } \\
\left(\mathrm{X}^{2}\right)\end{array}$} \\
\hline & $n$ & \multicolumn{3}{|c|}{ Genotypes frequency $(\%)$} & $\begin{array}{l}\text { Allele } \\
\text { frequency } \\
(\%)\end{array}$ & $n$ & \multicolumn{3}{|c|}{ Genotypes frequency $(\%)$} & $\begin{array}{l}\text { Allele } \\
\text { frequency } \\
(\%)\end{array}$ & \\
\hline$-109 \mathrm{C}>\mathrm{T}$ & 691 & 99.3 & 0.7 & 0 & 0.36 & 331 & 99.7 & 0.3 & 0 & 0.15 & $p>0.05$ \\
\hline$-69 \mathrm{C}>\mathrm{T}$ & 644 & 99.8 & 0.2 & 0 & 0.08 & 285 & 100 & 0 & 0 & 0 & $p>0.05$ \\
\hline P387L & 596 & 97.5 & 2.5 & 0 & 1.3 & 427 & 98.4 & 1.6 & 0 & 0.8 & $p>0.05$ \\
\hline
\end{tabular}

For each SNP, we named " $1 / 1$ " the homozygous wild-type genotype, "2/2" the homozygous mutated genotype and " $1 / 2$ " the heterozygous genotype

polymorphisms were in Hardy-Weinberg equilibrium in obese and control groups. The most frequent SNP, IVS5+3666delT, showed an increased +3666delT allele frequency in the obese group compared with the control group (Table 3). IVS5+3666delT showed a significant association with morbid obesity $(p=0.02$, chi square test done with genotypes data). This SNP was more tightly associated with obesity in a dominant +3666delT allele model. Carriers of the variant allele (genotypes +3666delT/+3666delT and $+3666 \mathrm{delT} / \mathrm{T}$ ) are more prevalent in the obese group than in the control group $(75.5 \%$ vs $67.5 \%, p=0.007$; $\mathrm{OR}=1.49$ [1.11-1.99]). When considering only nondiabetic obese subjects $(n=440)$, the association was similar (data not shown). Calculation of the retrospective power for IVS5+3666delT case-control study showed an allelic frequency of $36 \%$ in the obese group compared with the control group, with a statistical power of 0.8 and a type error of 0.05 (two-sided).

The variant alleles of $-109 \mathrm{C}>\mathrm{T}, \mathrm{P} 303 \mathrm{P}$ and P387L SNPs also showed increased allelic frequencies in the obese group compared with the non-obese group but the difference was not statistically significant (Table 3).

IVS5+3666delT and P303P SNPs were in linkage disequilibrium $\left(\mathrm{D}^{\prime}>0.655, p<0.001\right)$ as were $\mathrm{P} 303 \mathrm{P}$ and P387L SNPs $\left(\mathrm{D}^{\prime}>0.422, p<0.001\right)$, although these alleles are quite rare. Haplotype analysis was carried out for the most frequent SNPs, IVS5+3666delT and P303P $(\mathrm{C}>\mathrm{T})$. The four corresponding haplotypes (T-C, delT-C, delT-T and T-T) accounted for more than $98.5 \%$ of all chromosomes. Differences in haplotype frequencies were observed between the obese and the control group (T-C: $65.4 \%$ vs $74.6 \%$; delT-C: $27.3 \%$ vs $21.2 \%$; delT-T: $6.4 \%$ vs $3.5 \%$ and T-T: $0.9 \%$ vs $0.7 \% ; p=0.005)$. As expected, the two haplotypes including the +3666delT allele, delT-C and delT-T were increased in the obese group and so associated with obesity.

Associations of PTP $1 B$ gene SNPs with metabolic syndrome traits. We further evaluated the influence of
PTP $1 B$ SNPs on the development of obesity-related phenotypes in obese patients. All traits were first analysed qualitatively and separately considering the diabetic, hypertensive and dyslipidaemic status of obese patients. Particular attention was taken to avoid potential confounding effects by checking homogeneity of age, sex and BMI in the subgroups. Analyses were adjusted when necessary. No association was observed with Type 2 diabetes, hypertension and dyslipidaemia (data not shown). The obese group was further stratified according to metabolic syndrome status. Again, no association was found for all SNPs.

When quantitative data were analysed, we excluded patients treated for Type 2 diabetes, hypertension and dyslipidaemia. To avoid possible selection bias, we evaluated genotypes and allelic frequencies in each truncated group. We found no differences in allelic or genotype frequencies and so consider that the selected group was representative of the whole obese group (data not shown). P303P and P387L were associated with modifications of lipid parameters in obese subjects. P303P TT carriers had lower apolipoprotein A1 levels than $\mathrm{CT}$ and $\mathrm{CC}$ carriers $(1.25 \pm 0.09,1.49 \pm 0.02$ and $1.47 \pm 0.01 \mathrm{~g} / \mathrm{l}$ in TT $[n=8]$, CT $[n=82]$ and CC $[n=384]$ respectively, $p=0.05)$. Furthermore, P387L T allele was associated with higher triglyceride $(p=0.0003)$, apolipoprotein $\mathrm{B}(p=0.09)$ and lipoprotein a $(p=0.0063)$ levels (Fig. 2). We did not observe any association between P303P and P387L SNPs and the other clinical traits including BMI, WHR, systolic and diastolic blood pressure, and other metabolic parameters such as glycaemia, insulinaemia, insulin resistance indices and cholesterolaemia (data not shown).

We only found five allele $\mathrm{T}$ carriers of $-109 \mathrm{C}>\mathrm{T}$ SNP. Compared with CC genotypes, these allele T carriers had lower waist to hip ratios $(0.81 \pm 0.07$ vs $0.93 \pm 0.004, \quad p=0.016)$, systolic blood pressure $(120 \pm 4.0 \mathrm{~mm} \mathrm{Hg}$ vs $131 \pm 0.8 \mathrm{~mm} \mathrm{Hg}, p=0.063)$ and diastolic blood pressure $(60 \pm 0.6 \mathrm{~mm} \mathrm{Hg}$ vs $76 \pm$ $0.6 \mathrm{~mm} \mathrm{Hg}, p=0.005)$. The $-69 \mathrm{C}>\mathrm{T}$ variant was found in one non-diabetic obese subject. Only 15 family members of the proband could be analysed. Carri- 

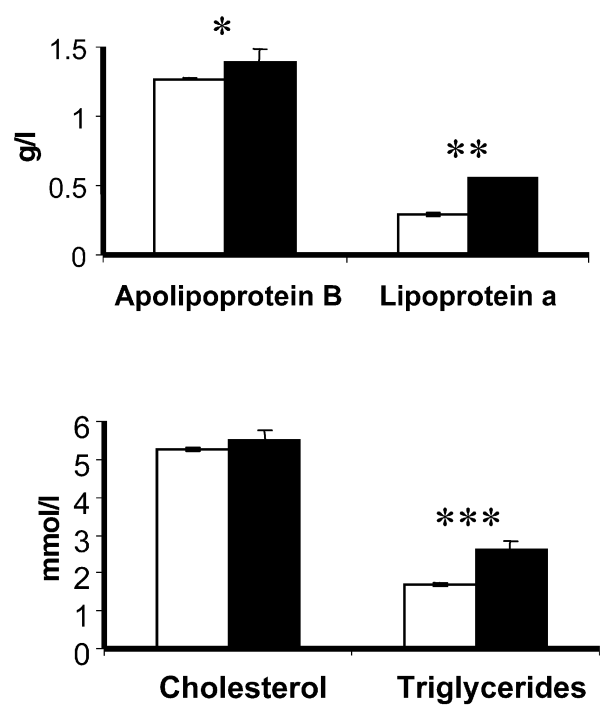

Fig. 2. Association study between P387L SNP and lipid parameters in the obese group. CT (black bars): $n=13$; CC (white bars): $n=461$. Values: apolipoprotein B: $1.27 / 1.39 \mathrm{~g} / \mathrm{l}$ (CC/CT); lipoprotein a: 0.29/0.55 g/l (CC/CT); cholesterol: 5.28/5.51 mmol/1 (CC/CT); triglycerides: $1.7 / 2.6 \mathrm{mmol} / \mathrm{l} \quad$ (CC/CT). $* p=0.09$, $* * p=0.006, * * * p=0.0003$

ers of the rare $\mathrm{T}$ allele, three of the five children of the proband, showed trends of higher birthweight, BMI, maximal BMI reached, cholesterol, lipoprotein a and apolipoprotein B than CC genotypes in this family (data not shown).

\section{Discussion}

We identified four new variants in the $P T P 1 B$ gene in addition to the two polymorphisms in the coding sequence already reported. The new IVS5+3666delT SNP, with the highest allelic frequency, was associated with morbid obesity in this French cohort of 711 subjects. The association with morbid obesity was found in a situation where we compared two populations with extreme phenotypes (i.e. morbidly obese patients and healthy controls who had never been obese and thus could be considered supra-normal controls). In genetic study of complex diseases, selecting extreme phenotypes is a useful strategy because it confers more power on the analysis. Although this strategy was first proposed in a situation where the quantitative distribution of a given trait is analysed in a family context, it has been sugggested that the use of extremely discordant phenotypes is efficient in sample-based case control design [28].

Allelic frequencies of $-109 \mathrm{C}>\mathrm{T}, \mathrm{P} 303 \mathrm{P}$ and P387L SNPs were increased in the obese group compared with the non-obese group. The allelic frequency of the previously found P387L mutation in the French population was very close to that described in the Danish population showing association in a subject with Type 2 diabetes. Many factors such as population het- erogeneity, sample size or gene environment may contribute to variable association results. As previously done for PPAR $\gamma$ Pro12Ala SNP [29], a meta-analysis taking account of several different populations should probably be carried out for this gene. Increasing numbers of concordant studies $[18,19,20]$ in Caucasian populations, including ours, suggest that PTP 1B might contribute to obesity and metabolic syndrome traits. The association between PTP 1B SNP and obesity might be consistent with recent animal studies showing that PTP 1B could contribute to the enlargement of adipocyte stores and to the development of obesity $[11,13]$.

Among the French obese subjects, $P T P 1 B$ variants were also associated with obesity-related traits such as dyslipidaemia. P303P and P387L SNPs were associated with higher triglyceride, apolipoprotein B and lipoprotein a levels and lower lipoprotein A1 levels, which may confer increased atherogenicity on the carriers of the variant allele [30]. The fact that none of the PTP 1B variants were associated either with Type 2 diabetes development or with modified glucose/insulin parameters in our population merits consideration. Morbid obesity is evidently an insulinresistant state, and therefore it is highly possible that the potential effect of PTP 1B variants on carbohydrate metabolism could be masked [31]. The fact that PTP 1B polymorphisms had no significant effect on basal glucose/insulin parameters in our populations does not exclude the possibility that some allelic effects become apparent during the post-prandial state, dietary modification or therapeutic intervention.

In addition to its role in insulin sensitivity via insulin cascade protein dephosphorylation, PTP 1B may regulate lipogenic genes. PTP $1 \mathrm{~B}$ may up-regulate SREBP-1 expression, thus mediating hepatic lipogenesis and postprandial hypertriglyceridaemia [15]. PTP 1B antisense treatment can also modulate fat storage and lipogenesis in adipose tissue [13]. Thus, the observed SNP-associated dyslipidaemia could result from modification of PTP 1B activity. IVS5+3666delT SNP might be functional or in LD with a nearby unidentified functional mutation. In the coding region, $\mathrm{P} 387 \mathrm{~L}$ was the only one to be studied at the functional level. This variant was associated with impaired phosphorylation of Serine 386, a target of a proline-directed p $34^{\mathrm{cdc} 2}$ protein kinase [18]. However, the phosphorylation role of Serine 386 in PTP 1B activity is unclear. Some authors have described a decreased PTP 1B activity when it is phosphorylated [32], whereas others described the opposite [33]. Further studies are necessary to clarify P387L variant functional consequences on PTP $1 \mathrm{~B}$ function. The two rare mutations, $-69 \mathrm{C}>\mathrm{T}$ and $-109 \mathrm{C}>\mathrm{T}$, are located in the $5^{\prime} \mathrm{UTR}$ region, known to influence various aspects of mRNA metabolism (processing, export, stability and translational control) [34]. Comparison of human and mouse PTP $1 B$ regions upstream of the 
ATG showed only $57.4 \%$ homology with several conserved GC-rich sequences [35] that contain these SNPs. Further functional analysis is necessary to appreciate the possible consequences of these rare SNPs on PTP 1B gene expression.

Our results support the hypothesis that $P T P 1 B$ polymorphisms contribute to obesity in obese French subjects. Moreover, PTP $1 B$ SNPs may interact with environmental risk factors (obesity, diet etc.) to contribute to the development of several features of atherogenic dyslipidaemia in obese subjects.

Acknowledgments. S. Kipfer-Coudreau and D. Eberlé contributed equally to this work. This work was supported by the Direction de la Recherche Clinique/Assistance Publique-Hopitaux de Paris, the Programme Hospitalier de Recherche Clinique (AOM 96088), the Servier Research Institute (IRIS) and the Claude Bernard Association. We thank Annie Le Gall and Véronique for technical help. We are indebted to Serge Hercberg and the SUVIMAX team for giving access to the Danone/SUVIMAX DNA Bank.

\section{References}

1. Reaven G (2002) Metabolic syndrome: pathophysiology and implications for management of cardiovascular disease. Circulation 106:286-288

2. Haffner S, Taegtmeyer H (2003) Epidemic obesity and the metabolic syndrome. Circulation 108:1541-1545

3. Reaven G (1988) Role of insulin resistance in human disease. Diabetes 37:1595-1607

4. Meigs JB, D'Agostino RBS, Wilson PW et al. (1997) Risk variable clustering in the insulin resistance syndrome. The Framingham Offspring Study. Diabetes 6:1594600

5. Hanley AJ, Karter AJ, Festa A et al. (2002) Factor analysis of metabolic syndrome using directly measured insulin sensitivity: the Insulin Resistance Atherosclerosis Study. Diabetes 51:2642-2647

6. White MF (1994) The IRS-1 signaling system. Curr Opin Genet Dev 4:47-54

7. White MF, Kahn CR (1994) The insulin signaling system. J Biol Chem 269:1-4

8. Seely BL, Staubs PA, Reichart DR et al. (1996) Protein tyrosine phosphatase $1 \mathrm{~B}$ interacts with the activated insulin receptor. Diabetes 45:1379-1385

9. Worm D, Vinten J, Beck-Nielsen H (1999) The significance of phosphotyrosine phosphatase (PTPase) 1B in insulin signalling. Diabetologia 42:1146-1149

10. Ukkola O, Santaniemi M (2002) Protein tyrosine phosphatase 1B: a new target for the treatment of obesity and associated co-morbidities. J Intern Med 251:467-475

11. Elchebly M, Payette P, Michaliszyn E et al. (1999) Increased insulin sensitivity and obesity resistance in mice lacking the protein tyrosine phosphatase-1B gene. Science 283:1544-1548

12. Klaman LD, Boss O, Peroni OD et al. (2000) Increased energy expenditure, decreased adiposity, and tissue-specific insulin sensitivity in protein-tyrosine phosphatase 1B-deficient mice. Mol Cell Biol 20:5479-5489

13. Rondinone CM, Trevillyan JM, Clampit J et al. (2002) Protein tyrosine phosphatase $1 \mathrm{~B}$ reduction regulates adiposity and expression of genes involved in lipogenesis. Diabetes $51: 2405-2411$
14. Osborne TF (2000) Sterol regulatory element-binding proteins (SREBPs): key regulators of nutritional homeostasis and insulin action. J Biol Chem 275:32379-32382

15. Shimizu S, Ugi S, Maegawa H et al. (2003) Protein-tyrosine phosphatase $1 \mathrm{~B}$ as new activator for hepatic lipogenesis via sterol regulatory element-binding protein-1 gene expression. J Biol Chem 44:43095-43101

16. Brown-Shimer S, Johnson KA, Lawrence JB et al. (1990) Molecular cloning and chromosome mapping of the human gene encoding protein phosphotyrosyl phosphatase 1B. Proc Natl Acad Sci USA 87:5148-5152

17. Lembertas AV, Perusse L, Chagnon YC et al. (1997) Identification of an obesity quantitative trait locus on mouse chromosome 2 and evidence of linkage to body fat and insulin on the human homologous region 20q. J Clin Invest 100:1240-1247

18. Echwald SM, Bach H, Vestergaard H et al. (2002) A P387L variant in protein tyrosine phosphatase-1B (PTP-1B) is associated with type 2 diabetes and impaired serine phosphorylation of PTP-1B in vitro. Diabetes 51:1-6

19. Mok A, Cao H, Zinman B et al. (2002) A single nucleotide polymorphism in protein tyrosine phosphatase PTP-1B is associated with protection from diabetes or impaired glucose tolerance in Oji-Cree. J Clin Endocrinol Metab 87:724-727

20. Di Paola R, Frittitta L, Miscio G et al. (2002) A variation in $3^{\prime}$ UTR of hPTP1B increases specific gene expression and associates with insulin resistance. Am J Hum Genet 70:806-812

21. Clement K, Vaisse C, Manning BS et al. (1995) Genetic variation in the beta 3-adrenergic receptor and an increased capacity to gain weight in patients with morbid obesity. N Engl J Med 333:352-354

22. Laaksonen DE, Lakka HM, Niskanen LK, Kaplan GA, Salonen JT, Lakka TA (2002) Metabolic syndrome and development of diabetes mellitus: application and validation of recently suggested definitions of the metabolic syndrome in a prospective cohort study. Am J Epidemiol 156:1070-1077

23. Hercberg S, Preziosi P, Briancon S et al. (1998) A primary prevention trial using nutritional doses of antioxidant vitamins and minerals in cardiovascular diseases and cancers in a general population: the SU.VI.MAX study-design, methods, and participant characteristics. SUpplementation en VItamines et Mineraux AntioXydants. Control Clin Trials 19:336-351

24. Mattews D, Hosker J, Rudenski A, Naylor B, Treacher D, Turner R (1985) Homeostasis model assessment: insulin resistance and beta-cell function from fasting plasma glucose and insulin concentrations in man. Diabetologia 28:412-419

25. Dubern B, Clement K, Pelloux V et al. (2001) Mutational analysis of melanocortin-4 receptor, agouti-related protein, and alpha-melanocyte-stimulating hormone genes in severely obese children. J Pediatr 139:204-209

26. Stephens M, Smith NJ, Donnelly P (2001) A new statistical method for haplotype reconstruction from population data. Am J Hum Genet 68:978-989

27. Slatkins M (1994) Linkage disequilibrium in growing and stable populations. Genetics 137:331-336

28. Morton NE, Collins A (1998) Tests and estimates of allelic association in complex inheritance. Proc Natl Acad Sci USA 95:11389-11393

29. Altshuler D, Hirschhorn JN, Klannemark M et al. (2000) The common PPARgamma Pro12Ala polymorphism is associated with decreased risk of type 2 diabetes. Nat Genet 26:76-80 
30. Vakkilainen J, Steiner G, Ansquer JC et al. (2003) Relationships between low-density lipoprotein particle size, plasma lipoproteins, and progression of coronary artery disease: the Diabetes Atherosclerosis Intervention Study (DAIS). Circulation 107:1733-1737

31. Kahn BB, Flier JS (2000) Obesity and insulin resistance. J Clin Invest 106:473-481

32. Flint AJ, Gebbink MF, Franza BR Jr, Hill DE, Tonks NK (1993) Multi-site phosphorylation of the protein tyrosine phosphatase, PTP1B: identification of cell cycle regulated and phorbol ester stimulated sites of phosphorylation. EMBO J 12:1937-1946
33. Schievella AR, Paige LA, Johnson KA, Hill DE, Erikson RL (1993) Protein tyrosine phosphatase 1B undergoes mitosis-specific phosphorylation on serine. Cell Growth Differ 4:239-246

34. Mendell JT, Dietz HC (2001) When the message goes awry: disease-producing mutations that influence mRNA content and performance. Cell 107:411-414

35. Forsell PA, Boie Y, Montalibet J, Collins S, Kennedy BP (2000) Genomic characterization of the human and mouse protein tyrosine phosphatase-1B genes. Gene 260:145153 